\title{
Individual and environmental determinants of daily black grouse nest survival rates at variable predator densities
}

\author{
Gilbert X. Ludwig ${ }^{1,2, \star}$, Rauno V. Alatalo ${ }^{1}$, Pekka Helle $^{3}$ \& Heli Siitari ${ }^{1}$ \\ 1) Department of Biological \& Environmental Science, P.O. Box 35, Fl-40014 University of \\ Jyväskylä, Finland \\ 2) Finnish Forest Research Institute, Juntintie 154, FI-77600 Suonenjoki, Finland (*corresponding \\ author's e-mail: gillbert.ludwig@metla.fi) \\ 3) Finnish Game and Fisheries Research Institute, Tutkijantie 2E, FI-90570 Oulu, Finland
}

Received 20 Apr. 2010, revised version received 24 Aug. 2010, accepted 25 Aug. 2010

Ludwig, G. X., Alatalo, R. V., Helle, P. \& Siitari, H. 2010: Individual and environmental determinants of daily black grouse nest survival rates at variable predator densities. - Ann. Zool. Fennici 47: 387-397.

Nest predation in ground nesting black grouse (Tetrao tetrix) inhabiting managed boreal forests is arguably the single most important cause of nesting failure. Little is known, however, about indirect effects of other factors, such as maternal or environmental properties, and to what extent maternal and habitat qualities interact with varying levels of predator densities. Using an information-theoretical approach, we studied maternal and environmental determinants of daily nest survival rates under variable predator densities of 210 individual black grouse hens in central Finland. Environmental determinants were far more important than maternal ones, and the effects were more apparent at higher predator densities. Keeping predator densities constant, daily nest survival rates increased with nest conspicuousness and increasing tree density, and were higher in undrained areas. While there was no difference between adults and juveniles, hens that invested more in egg size were more successful. Therefore, environmental factors and, to a lesser extent, maternal properties, indirectly affect nesting success especially when predator density is high. Modern forestry practices such as clear cutting and drainage are commonly linked to increased densities of predators such as foxes. Our results suggest that the nesting success of black grouse may further be indirectly affected by the same practices, the overall impact being a balance between the negative (e.g. drainage, clear-cutting) and the positive (reforestation, producing dense young forest stands) effects.

\section{Introduction}

Intensified agriculture and forest management have been among the main reasons of generally high densities of small predators - especially foxes (Vulpes vulpes) - throughout Fennoscandia for the past 50 years (e.g. Lindström et al.
1994). As shown for a wide array of bird species (Ricklefs 1969, Martin 1995), nest predation is the single most important cause of nesting failure in ground-nesting forest grouse (Tetraonidae) (Bernard 1982, Brittas \& Willebrand 1992), and hence the temporal increase in fox densities is likely to have affected the long-term reproduc- 
tive success of grouse (Ludwig 2007). Furthermore, predation can hold population size of prey species below their carrying capacity and may cause long-term population declines (Marcström et al. 1988, Thirgood et al. 2000). Indeed, in much of Fennoscandia, both long-term breeding success and size of grouse populations faced severe decline during the past decades (Helle et al. 2002, Ludwig et al. 2006).

The decline in grouse breeding success are commonly associated with increased rates of nest predation, especially by mammalian predators (Marcström et al. 1988, Baines 1991, Caizergues \& Ellison 1997, Kurki et al. 1997, 1998, Kauhala \& Helle 2002). In Fennoscandia, two hypotheses are generally put forward to explain the observed increases in predation pressures. First, intensified agricultural activities have increasingly fragmented the forest landscape, which has been shown to increase local densities of mesopredators like foxes (Vulpes vulpes) (Andrén et al. 1985, Kurki \& Lindén 1995, Huhta 1996, Kurki et al. 1998, 2000), or avian nest predators, such as corvids (Andrén 1992). Second, recent intensification of forest management, e.g. by clear cutting, have increased the proportion of young successional forest stages that are rich in grass-dominated undergrowth (Esseen et al. 1992, Hansson 1992). Such habitats have been shown to attain very high densities of Microtus voles, much higher than those of original forest rodent species (such as Myodes glareolus) (Henttonen 1989). Since Microtus are preferred prey of many generalist predators, such areas may sustain higher densities of their predators (Hansson \& Henttonen 1988, Angelstam 1992, Kurki et al. 1998). Furthermore, a negative effect of large-scale drainage on grouse breeding success has recently been demonstrated (Ludwig et al. 2008).

While nest predation is the most important direct, or ultimate, cause of nest loss in grouse, little is known about the indirect, or proximate, effects of other factors, such as maternal or environmental properties and the extent to which maternal and habitat qualities interact with varying levels of predation. That is, at any given predator density, both maternal properties, such as body mass or age, and habitat properties, such as e.g. vegetation characteristics, may affect the probability of nest loss. These questions are especially relevant in the context of landscapes altered by humans, since changes in the habitat structure may not only affect predator densities locally, but may also alter the perception of predation risk and hence the selection pressure thereof.

In this study, we use an information-theoretic model selection procedure to investigate proximate causes of nest loss, i.e. the ones potentially under selection, at varying predator densities in the ground-nesting and precocial black grouse (Tetrao tetrix) in heavily managed forest landscapes of Fennoscandia. We defined the actual depredation event as the ultimate cause of nest loss, while indirect effects were defined as the properties of the individual hen (e.g. body mass or parasite infestation) or the nesting environment (e.g. vegetation characteristics), which may have affected the probability of depredation.

\section{Material and methods}

\section{Field methods}

We monitored the nesting success of individual black grouse hens in the surroundings of a total of 9 different leks in central Finland $\left(62^{\circ} 25^{\prime} \mathrm{N}, 25^{\circ} 20^{\prime} \mathrm{E}\right)$ during $2003-2006$. The sites were located in the communes of Jyväskylä Maalaiskunta, Jämsänkoski, Keuruu, Multia and Petäjävesi. The entire study area covered about $4000 \mathrm{~km}^{2}$, the farthest distance between two sites being approximately $100 \mathrm{~km}$. We captured hens in winters (December-March) and once during the lekking in end of April 2003 from feeding sites on the leks using oat-baited walk-in traps (Alatalo et al. 1996). After capturing, hens were aged and classified as either yearlings or adults on the basis of shape and weariness of the outermost primary wing feathers (Helminen 1963), and weighed to the nearest $0.01 \mathrm{~kg}$ (Pesola Spring Balance). Because hens gain weight rapidly just prior to the breeding season (April), body mass of the hens captured during the lekking time (end of April 2003) were adjusted by subtracting the average increase of body mass. Blood samples were taken by puncturing the brachial vein, from which we counted the number 
of the two most common extracellular blood parasites, microfilaria (Höglund et al. 1992) and Trypanosoma spp. (Rätti et al. 1993) according to Lebigre (2008). Because of the highly skewed distribution of Trypanosoma, we defined this variable on a prevalence basis. We also used blood samples to determine haematocrit (ht) levels of the birds by measuring the relative amount of red blood cells in the total volume of blood sampled (Lebigre 2008). Hens were fitted with a necklace-mounted radio transmitter [Televilt or Holohil, weight 15-20 g (1.7\%-2.2\% of mean body mass), life expectancy 18-24 months].

We located hens by radiotracking them at their nest at the beginning of the incubation period. When visiting the nests, we recorded the hen's escape distance (in meters), the clutch size and measured the weight of eggs with a Pesola balance (accuracy $\pm 0.1 \mathrm{~g}$ ). We approximated the timing of hatching on the basis of previous investigations (authors' unpubl. data), for which we estimated the incubation status by floating the eggs in hand-warm water. We approximated nest initiation date by calculating the onset of egg laying as follows:

$$
\mathrm{ELD}=\mathrm{HD}-25-1.8(\mathrm{CS}-1)
$$

where ELD is the date when egg laying is initiated, HD is the hatching date (or calculated hatching date if depredated), 25 is the average length of the incubation period, 1.8 is the interval in days between successive eggs and CS is the clutch size. The nest initiation date was standardized so that the day when the first nest of the entire study was found was day 1 .

We revisited the nest on the day of estimated hatching to assess its destiny. In most cases, we could exactly identify the hatching date, as the chicks were mostly still in, or very close to the nest. If the brood had left, we located and captured the chicks and approximated the age on the basis of wing-feather development. In this way, the day of hatching could always be estimated with \pm 1 -day accuracy. A nest was declared successful if $\geq 1$ chick had left the nest. For unsuccessful nests, we visually evaluated the reason (abandon/predation) on the basis of eggshell remains and predator tracks. Re-nesting attempts were checked for but were excluded from the analyses because these cannot be treated independently from first nesting attempts. Similarly, if a hen nested in subsequent years, we only considered the nesting attempt of the first year.

After the hen and the brood had departed from the nest, we described the environment of the nest site. First, we sampled the ground and field layers from a $2 \times 2 \mathrm{~m}$ square placed around the nest, an measured coverage of different vegetation types and characteristics as proportions. For the ground layer this included moss, lichen and litter cover. We described the field layer using the following characteristics: proportions of bilberry, lingonberry, heather and the combined proportion of grasses and grassy vegetation. All proportions (accuracy 5\%) were arcsine-transformed. Secondly, we described the area surrounding the nest as follows: number of trees/hectare, wood volume/hectare and tree canopy cover (arcsinetransformed). We estimated the wood volume using the relascope method (e.g. Hyvämäki 2002). On the basis of observations and maps, we evaluated the drainage status (drained/undrained) of the nest site within a radius of $100 \mathrm{~m}$. We further estimated the visibility of the nest by placing a grouse-sized object in the nest, and evaluating the distance from which the nest can be seen from N, S, W and E, from a height of approximately 1 meter. We defined overall visibility as the geometric mean of the visibilities from the four directions.

We also calculated mean daily temperature and mean daily rainfall for the nesting period of each hen (starting from the onset of egg laying to hatching or calculated hatching). The data were obtained from the local weather station within our study area run by the Finnish Meteorological Institute (contract no. DNO 1/410/03).

We estimated mammalian predator densities for fox, marten (Martes martes), stoat (Mustela erminea) and weasel (M. nivalis). At each of the sites, a polygon-shaped line transect of $10 \mathrm{~km}$ in length was investigated by skiing along the line in mid-winter. From 2003 to 2006 we investigated the lines on two subsequent days. On the first day, we had marked old predator tracks, and on the second we counted the new tracks that crossed the line. The polygon was situated so that it would encompass the majority of potential 
nesting areas around each of the lekking sites. Preliminary model runs (see below) revealed no effect of stoats and weasels, hence only fox and marten indices were used. Because indices of fox and marten were highly positively correlated we combined the two indices to characterize the overall predator density. We defined the index as the total number of tracks $/ 10 \mathrm{~km} \times 24$ hours. The method provides a reasonable proxy of relative density, and is essentially the same as the Finnish Wildlife Triangle Scheme, which has been proved very successful in a wide array of population studies on grouse (e.g. Lindén et al. 1996, Ludwig et al. 2006, Ludwig 2007) and their predators (e.g. Kurki et al. 1997, Reif et al. 2001, Byholm et al. 2007).

\section{Statistical analyses}

We estimate daily nest survival rates (hereafter DSR) using the nest survival model procedure and the logit link function of the program MARK. For every model, MARK produces the Akaike Information Criterion corrected for small sample size ( $\mathrm{AIC}_{\mathrm{c}}$ ) allowing models to be ranked according to the amount of information loss (Burnham \& Anderson 2002). For a given set of candidate models, the model with the lowest $\mathrm{AIC}_{\mathrm{c}}$ is considered the best, i.e. the model with least information loss. Differences in $\mathrm{AIC}_{\mathrm{c}}$ $\left(\Delta \mathrm{AIC}_{\mathrm{c}}\right)$, Akaike weight $(w)$ and deviance (dev) are presented as well.

All variables were checked for multicollinearity, and whenever pairs of independent variables were strongly correlated $(r \geq 0.4)$ one would be excluded based on the importance of the variable as established through previous research. The variables used in the candidate models were the following: predator track density, age of female, body mass, escape distance, clutch size, mean egg mass, haematocrite, microfilaria counts, Trypanosoma spp. prevalence, nest initiation date, moss coverage, litter coverage, bilberry coverage, lingonberry coverage, heather coverage, grassy vegetation coverage, tree density, canopy coverage, wood volume, nest visibility, drainage status, rainfall and temperature.

A model selection procedure was chosen that aims at identifying the relative importance of different covariates under varying predator densities, therefore we included predator track density in every model. In addition to predator track density, a maximum of two predictor variables were included at a time. Preliminary tests indicated that including year or site, or both, produced models that were inferior to the model including predator density only (in terms of $\mathrm{AIC}_{\mathrm{c}}$ ). All other predictor variables, when used as single main effect, performed worse than than the site/year model. This indicated that predator density accounts for most of the spatiotemporal variation in DSR. We, therefore, decided to use the predator track density model as a threshold model for further model selection. That is, from an information theoretic point of view, we are interested in all those models $i$ that fulfil the following condition:

$$
\mathrm{AIC}_{\mathrm{c} \_t \text { threshold }}-\mathrm{AIC}_{\mathrm{c} i} \geq 2
$$

From that group of models, even the worst are better, in terms of their $\mathrm{AIC}_{c}$, than the threshold model (Burnham \& Anderson 2002). In order to identify this subset of models, we run all possible models that included predator track density and any combination of a maximum of two predictor variables (total 276 models). Such a procedure commonly suffers from model selection uncertainty (Burnham and Anderson 2002). It needs to be understood, however, that we were mostly interested in the relative importance of predictor variables, rather than a particular "best" model. We, therefore, made further inference based on the entire subset of selected models. We present Akaike weights $\left(w_{i}\right)$ for each variable that is present in at least one selected model, and average the parameter estimates (and confidence intervals) across the models where a given variable occurs (Burnham $\&$ Anderson 2002). Whenever the $95 \%$ confidence interval of a parameter estimate includes zero then the predictor variable can be considered not important.

\section{Results}

During the four study years we found a total of 210 first nests that we used in the analyses. 
This excludes 5 nests that were possibly abandoned because of our visit. Overall nesting propensity was rather high throughout the period, being $93 \%$ on average (Table 1 ). Nesting success varied between years $\left(\chi^{2}=18.7\right.$ for observed nesting success, $p<0.001)$, being lowest when predator densities were the highest (2003) and the highest in 2005 and 2006, when fox and marten densities were at their lowest (Table 1). According to visual inspection of unsuccessful nests, predation was the most likely reason for nest loss in all cases. For reference, Table 2 lists means and standard errors for all continuous predictor variables used in the models, both for successful and unsuccessful nests.

A total of 20 DSR models fulfilled the condition of Eq. 2 (Table 3). The best model had an Akaike weight of 0.13 , suggesting strong model selection uncertainty (Burnham \& Anderson 2002). Hence, further inference was based on parameter averaging. Environmental variables occurred in all but one model, while maternal variables occurred in 8 out of 20 models. The sum of Akaike weights was 0.97 and 0.48 for environmental and maternal predictor variables, respectively.

Four predictor variables dominated: visibility $(w=0.595)$, drainage status $(w=0.557)$, mean egg mass $(w=0.306)$ and tree density $(w=$ 0.299) (Table 4). Figure 1 shows the effects of the most important predictor variables and predator density on DSR, separately for nests in drained and undrained areas. Other variables included in at least one model were (in order of importance) moss coverage, body mass, canopy, age, tem-
Table 2. Means (untransformed data) and standard errors of the continuous variables used in the models, both for successful and unsuccessful nests.

\begin{tabular}{|c|c|c|c|c|}
\hline \multirow[b]{2}{*}{ Variable } & \multicolumn{2}{|c|}{ Destroyed } & \multicolumn{2}{|c|}{ Hatched } \\
\hline & Mean & SE & Mean & SE \\
\hline Predator density & 9.50 & 1.50 & 4.30 & 0.50 \\
\hline Body mass & 874.28 & 5.73 & 886.97 & 3.41 \\
\hline Nest initiation date & 8.39 & 0.70 & 8.40 & 0.36 \\
\hline Clutch size & 9 & 0.00 & 9.06 & 0.00 \\
\hline Mean egg weight & 32.86 & 0.25 & 33.44 & 0.18 \\
\hline Escape distance & 2.40 & 0.30 & 1.90 & 0.10 \\
\hline Microfilaria & 36.41 & 6.97 & 40.13 & 4.76 \\
\hline Trypanosomes & 1.13 & 0.45 & 1.88 & 0.83 \\
\hline Haematocrite & 0.529 & 0.003 & 0.529 & 0.003 \\
\hline \multicolumn{5}{|l|}{ Percentage cover } \\
\hline Moss & 32.00 & 4.00 & 38.00 & 3.00 \\
\hline Litter & 68.00 & 4.00 & 63.00 & 35.00 \\
\hline Bilberry & 15.00 & 3.00 & 16.00 & 2.00 \\
\hline Lingonberry & 15.00 & 3.00 & 18.00 & 2.00 \\
\hline Heather & 6.00 & 2.00 & 7.00 & 1.00 \\
\hline Grassy vegetation & 32.45 & 5.38 & 32.75 & 3.14 \\
\hline Canopy & 32.00 & 4.00 & 40.00 & 3.00 \\
\hline Tree density & 10.03 & 1.33 & 14.13 & 9.00 \\
\hline Wood volume & 61.00 & 10.00 & 57.00 & 5.00 \\
\hline Visibility & 5.91 & 0.54 & 3.87 & 0.23 \\
\hline Temperature & 10.22 & 0.12 & 10.10 & 0.70 \\
\hline Precipitation & 2.35 & 0.16 & 1.79 & 0.09 \\
\hline
\end{tabular}

perature, litter cover and rain. In terms of their relative weights and confidence intervals, however, their effects seemed marginal at best. DSRs predicted for succesful nests were significantly higher than for unsuccessful nests (Mann-Whitney $U=2341.5, p<0.00001$; Fig. 2)

Table 1. Nest propensities, observed and corrected nest success, daily nest survival rates and predator track densities 2003-2006.

\begin{tabular}{|c|c|c|c|c|c|c|c|c|c|c|c|}
\hline \multirow[b]{2}{*}{ Year } & \multirow[b]{2}{*}{$n$} & \multicolumn{2}{|c|}{ Nest propensity ${ }^{a}$} & \multicolumn{2}{|c|}{ Observed $^{b}$} & \multicolumn{2}{|c|}{ Corrected $^{c}$} & \multicolumn{2}{|c|}{$\mathrm{DSR}^{\mathrm{d}}$} & \multicolumn{2}{|c|}{ Predators ${ }^{e}$} \\
\hline & & Mean & SE & Mean & SE & Mean & SE & Mean & SE & Mean & SE \\
\hline 2003 & 56 & 0.94 & 0.06 & 0.60 & 0.07 & 0.56 & 0.11 & 0.9766 & 0.005 & 15 & 1.3 \\
\hline 2004 & 41 & 0.98 & 0.04 & 0.68 & 0.07 & 0.67 & 0.09 & 0.9796 & 0.006 & 3.1 & 0.3 \\
\hline 2005 & 39 & 0.92 & 0.08 & 0.90 & 0.05 & 0.83 & 0.12 & 0.9941 & 0.003 & 0.7 & 0.1 \\
\hline 2006 & 74 & 0.90 & 0.03 & 0.86 & 0.04 & 0.77 & 0.06 & 0.9910 & 0.003 & 2.2 & 0.2 \\
\hline Total & 210 & 0.93 & 0.05 & 0.77 & 0.06 & 0.72 & 0.09 & 0.9854 & 0.002 & 5.5 & 0.5 \\
\hline
\end{tabular}

${ }^{a}$ Proportion of hens with nest to total number of hens found alive. ${ }^{b}$ Observed nest success: Proportion of successful nests to total number of nests. ${ }^{c}$ Corrected nest success: nest propensity multiplied by observed success. ${ }^{\mathrm{d}}$ Daily survival rate. ${ }^{e}$ Combined density of fox and marten tracks (tracks $/ 10 \mathrm{~km} \times 24 \mathrm{~h}$ ). 
Table 3. Best models of nest DSR in decreasing order of importance. $\mathrm{AIC}_{\mathrm{c}}=$ Akaike Information Criterion, $\triangle \mathrm{AIC} \mathrm{c}_{\mathrm{c}}=$ Difference in AIC as compared with the best model, $w=$ Akaike weight (see text for details). Note that each model also includes predator density. ${ }^{*}$ The predator-only model is shown as a reference.

\begin{tabular}{|c|c|c|c|c|c|c|}
\hline Model & $\mathrm{AlC}_{\mathrm{c}}$ & $\Delta \mathrm{AIC}_{\mathrm{c}}$ & $w$ & Likelihood & Deviance & $\begin{array}{l}\text { Number of } \\
\text { parameters }\end{array}$ \\
\hline Tree density, drainage status & 220.20 & 0.00 & 0.130 & 1.00 & 212.19 & 4 \\
\hline Drainage status, mean egg mass & 220.55 & 0.35 & 0.109 & 0.84 & 212.54 & 4 \\
\hline Drainage status, visibility & 220.56 & 0.36 & 0.108 & 0.83 & 212.55 & 4 \\
\hline Moss, visibility & 220.79 & 0.59 & 0.097 & 0.74 & 212.78 & 4 \\
\hline Mean egg mass, visibility & 221.23 & 1.03 & 0.077 & 0.60 & 213.22 & 4 \\
\hline Tree density, visibility & 221.24 & 1.04 & 0.077 & 0.60 & 213.22 & 4 \\
\hline Tree density, mean egg mass & 221.88 & 1.68 & 0.056 & 0.43 & 213.87 & 4 \\
\hline Body mass, drainage status & 222.60 & 2.40 & 0.039 & 0.30 & 214.58 & 4 \\
\hline Body mass, visibility & 222.62 & 2.42 & 0.039 & 0.30 & 214.61 & 4 \\
\hline Canopy, drainage status & 222.93 & 2.73 & 0.033 & 0.26 & 214.91 & 4 \\
\hline Drainage status & 223.11 & 2.90 & 0.030 & 0.23 & 217.10 & 3 \\
\hline Visibility & 223.38 & 3.18 & 0.026 & 0.20 & 217.37 & 3 \\
\hline Mean egg mass & 223.39 & 3.19 & 0.026 & 0.20 & 217.38 & 3 \\
\hline Age, drainage status & 223.42 & 3.22 & 0.026 & 0.20 & 215.41 & 4 \\
\hline Visibility, temp & 223.63 & 3.43 & 0.023 & 0.18 & 215.62 & 4 \\
\hline Litter, visibility & 223.65 & 3.45 & 0.023 & 0.18 & 215.64 & 4 \\
\hline Moss, drainage status & 223.77 & 3.57 & 0.022 & 0.17 & 215.76 & 4 \\
\hline Canopy, visibility & 223.79 & 3.59 & 0.022 & 0.17 & 215.77 & 4 \\
\hline Age, visibility & 224.10 & 3.90 & 0.018 & 0.14 & 216.08 & 4 \\
\hline Visibility, rain & 224.10 & 3.91 & 0.018 & 0.14 & 216.09 & 4 \\
\hline Predator density* & 226.14 & 5.94 & & & 222.13 & 2 \\
\hline
\end{tabular}

\section{Discussion}

Predation was the cause of nest loss and hence of reproductive failure in all studied cases. Although nesting success varied considerably among sites

Table 4. Averaged Akaike weights $\left(w_{\text {hat }}\right)$, averaged parameter estimates $\left(\beta_{\text {hat }}\right)$, and their standard errors $\left(\mathrm{SE}_{\text {hat }}\right)$, lower $\left(\mathrm{LCl}_{\text {hat }}\right)$ and upper $\left(\mathrm{UCl}_{\text {hat }}\right)$ confidence intervals. Note that predator track density is included in all models (see Material and methods for details).

\begin{tabular}{lrrrrr}
\hline & $w_{\text {hat }}$ & $\beta_{\text {hat }}$ & $\mathrm{SE}_{\text {hat }}$ & $\mathrm{LCl}_{\text {hat }}$ & $\mathrm{UCl}_{\text {hat }}$ \\
\hline $\begin{array}{l}\text { Constant } \\
\text { Predation }\end{array}$ & 1.000 & 2.869 & 1.299 & 0.223 & 5.315 \\
Visibility & 0.595 & -0.045 & 0.163 & -0.755 & -0.117 \\
$\begin{array}{l}\text { Drainage } \\
\quad \text { status }\end{array}$ & 0.557 & 0.605 & 0.031 & -0.139 & -0.018 \\
Mean egg & & & & 0.075 & 0.847 \\
$\quad$ mass & 0.306 & 0.157 & 0.076 & 0.009 & 0.305 \\
Tree density & 0.299 & 0.003 & 0.001 & 0.000 & 0.005 \\
Moss & 0.135 & 0.584 & 0.301 & -0.007 & 1.175 \\
Bodymass & 0.078 & 5.772 & 3.557 & -1.200 & 12.745 \\
Canopy & 0.062 & 0.576 & 0.421 & -0.249 & 1.402 \\
Age & 0.044 & 0.381 & 0.305 & -0.217 & 0.979 \\
Temperature & 0.027 & 0.271 & 0.207 & -0.135 & 0.678 \\
Litter & 0.026 & -0.459 & 0.354 & -1.152 & 0.235 \\
Rain & 0.021 & 0.288 & 0.262 & -0.225 & 0.802 \\
\hline
\end{tabular}

and years, the predator-only model was the only single main-effect model that performed better than models including site and/or year, suggesting that this variation is due to the spatial-temporal variation in the distribution of predators. Given this context, we show that the environmental properties of the selected nest site may act as indirect effects, i.e. modulate the risk of nest loss due to predation. From a habitat selection perspective, hens should therefore select undrained areas with high tree density and select a specific nest site with low visibility, especially when predator densities are high. This is likely to be an adaptation to mammalian predator behaviour. Mammalian predators are generally not very efficient in finding grouse nests, e.g. for hunting dogs the detection distance of black grouse nests has been shown to be less than $2 \mathrm{~m}$ (Storaas et al. 1999). Second, grouse nests are commonly distributed quasi randomly in many different habitat types (Storaas \& Wegge 1987). High visibility of the nest and low tree density possibly increase the detection radius, and/or increase the screening efficiency of the predator, and hence the probability of finding and depredating the nest. Furthermore, predators may frequent open areas 

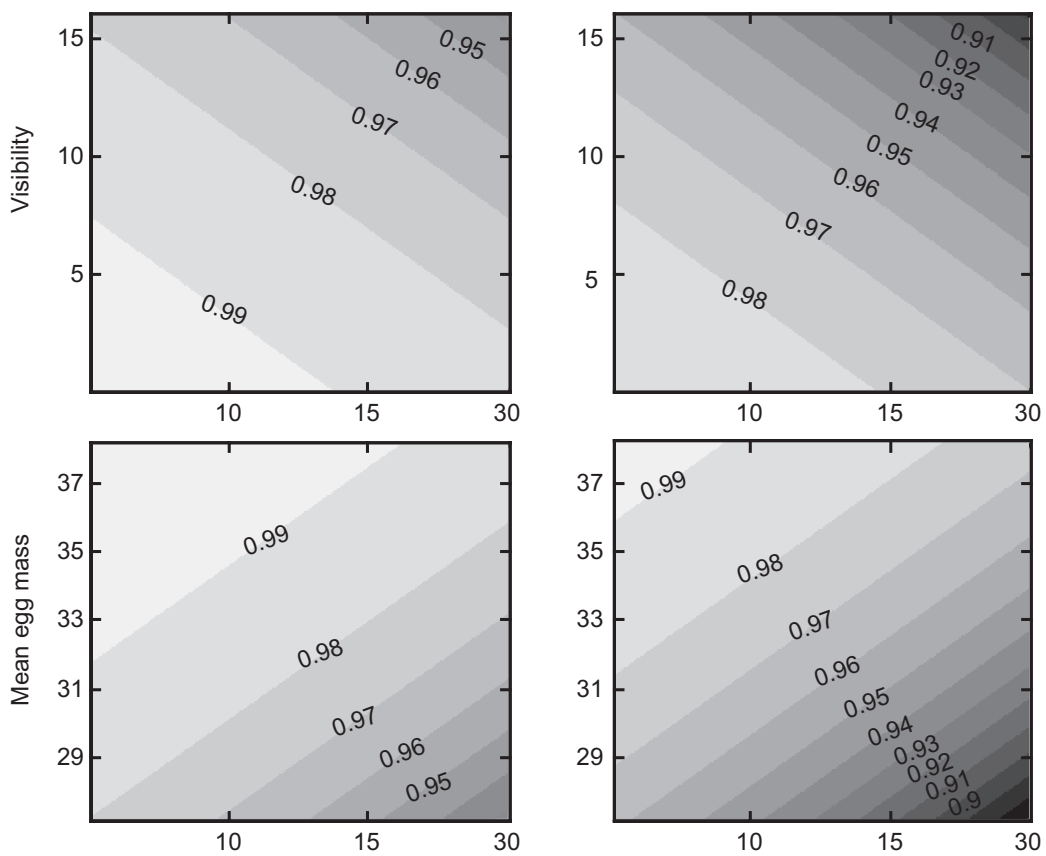

Fig. 1. Contour plots of daily nest survival rates (DSR) as functions of visibility, mean egg mass and tree density under varying predator densities in undrained (left-hand-side column) and drained (lefthand-side right column) habitats.
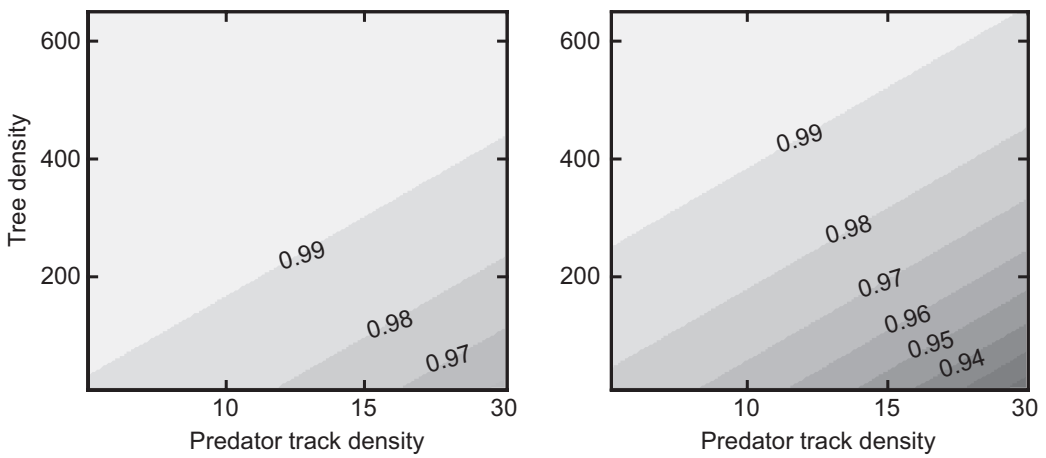

with high visibility more often than areas with dense vegetation. However, the composition of what provides the cover, i.e. reduces nest visibility, does not seem to be important. Of the habitat features that potentially provide such cover, only tree density was included in one of the best models, but it was not correlated with visibility. High tree density is associated with trees of young age, which are normally thin and provide little cover on the ground and field layers, hence do not necessarily decrease nest visibility. However, predators may avoid dense tree stands, as these are possibly less efficient searching grounds for predators. Overall, the best model(s) predicted DSRs, and hence nest fate, very well (Fig. 2).

Nests in drained areas further had a higher risk of predation, even at moderate predator den-

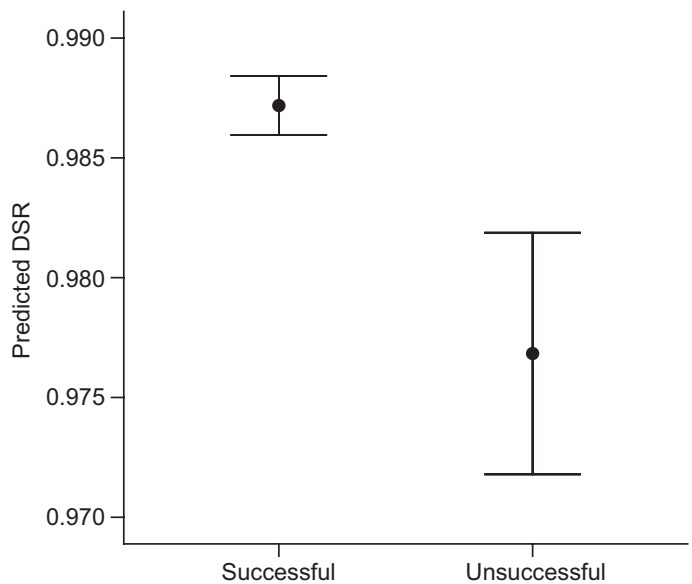

Fig. 2. Predicted daily nest survival rates $( \pm 95 \% \mathrm{Cl})$ for observed successful and unsuccessful nests. 
sities (Fig. 1). We have recently demonstrated a negative effect of drainage on breeding success in three forest grouse species (Ludwig et al. 2008). While the mechanisms through which drainage affects breeding success remained elusive, we argued that drainage should mostly affect the brood rearing stage. Our new results here suggest that the drainage effect may arise, or be reinforced, by decreasing nesting success. The effect could be related to a higher search efficiency related to the fragmented pattern provided by network of ditches. For predators known to benefit from fragmentation, such as foxes (Kurki et al. 1998) or corvid birds (Andrén 1992) foraging may be more efficient in drained areas. Storaas et al. (1999) showed that predation on grouse broods could be explained by fragmentation alone, even without increased predator densities. The same might apply here for grouse nests.

Maternal predictor variables were noticeably less important in mediating the risk of nest loss. Willebrand (1992) reported an age effect, with first breeders being significantly less successful than older hens. In another Finnish study, however, Marjakangas and Törmälä (1997) found no such effect. Similarly, our results did not reveal any differences in DSR between first breeders and older hens. Hens investing in larger eggs, however, were more successful. This is intriguing, since first breeders produced on average smaller eggs than old hens, yet there was no effect of age on daily nest survival rates. The ecological mechanism underlying the effect of egg size remains therefore unclear. According to Siivonen (1958), warm springs provide more food during the pre-egg laying stage and therefore hens may then produce larger eggs. The years 2005 and 2006 had both warmer springs and lower predator densities than 2003 and 2004, and hens indeed produced, in average, larger and heavier eggs in the two last years. The effect of egg size on nest on DSR could therefore be an artefact related to climatic conditions.

Seven other variables (moss and litter coverage, canopy, temperature, precipitation, age and bodymass) were included in at least one of the best models. Their low average Akaike weight as well as confidence intervals including zero, however, suggest low importance, if any. Of the variables not included in the best models, blood parasites are worth mentioning. In red grouse (Lagopus lagopus scoticus), increased parasite load has been shown to affect nesting success directly (Hudson 1986), and heavily infested birds were more vulnerable to predation (Hudson et al. 1992). However, these were intestinal and not blood parasites. Also, red grouse is a heavily managed game species that may reach very high densities (Hudson et al. 1992). Black grouse in Fennoscandia occur naturally at much lower densities, likely too low for parasite transmission (blood or intestinal) to be efficient enough .

The modern boreal forest landscape is largely a product of modern and efficient forest management aimed at maximizing timber production. Our study suggests that the resulting mosaic of forest patches at different successional stages provides good potential nesting habitat for black grouse, as long as there is adequate cover around the nest. Such habitat, on the other hand, is increasingly associated with a number of dangers, such as increased densities of small mammalian predators or corvid birds. Also, according to our results, other features of the modern forest landscape such as large-scale drainage may further reinforce the negative impact of predation, but may affect breeding success also directly (Ludwig et al. 2008). Kurki et al. (2000) demonstrated a positive (and scale dependent) relationship between black grouse breeding success and the proportion of old to young forest. At first glance, this seems counterintuitive, as black grouse prefer young forests. However, this is likely to be due to the finding that both the extent of fragmentation and the density of small predators and corvids are inversely related to the proportion of old forest. In other words, although black grouse prefer young forests, the proportional increase of young forest stages may lead to increased risks (e.g. predation) which outweigh the potential advantages (e.g. increase in the surface of potential breeding habitats). We may therefore argue that we have a case of an ecological or evolutionary trap (Schlaepfer et al. 2002).

From an applied point of view, our results suggest that the two most important means of forestry management, clear-cutting and drainage of bog land, to be mainly unfavorable for grouse nesting. Alternative forest management strategies 
may involve, for instance, a shift from clearcutting at low frequencies to partial clear cutting at higher frequencies. This may reduce the extent of local fragmentation and open areas and produce forest patches that are more diverse in terms of their age structure. Furthermore, although the establishment of new ditch systems for draining bogs has ceased, existing ditch systems are commonly maintained. In the case when results of local drainage, in terms timber production, are not profitable, maintenance of ditch systems is commonly abandoned. The effect of abandoned ditches, however, is likely to remain for years or even decades after abandon. To prevent this from happening, for instance, ditches may be refilled, which after some time would restore the original state of the bog. Such actions have been practiced with success in a long-term program of bog restoration, conducted by the Finnish Park and Forest service, in national parks and other state owned land (Heikkilä et al. 1997). In privately owned forests, however, such procedures are yet rare.

Finally, it has been shown for number of bird species that breeding individuals may be able to perceive predation risk and adapt reproductive investment and nest site selection accordingly. In passerines for instance, it has been reported that parents may adapt their investment in young according to perceived increases in predation risk by decreasing egg mass (Fontaine and Martin 2006a) or clutch size (Eggers et al. 2005). If there is a lot of variation in predator density, habitat decisions are critical and birds may choose sites that minimize the cost of predation (Jaenike \& Holt 1991, Martin 1992, 1998, Morris 2003, Fontaine \& Martin 2006b). Selective pressures induced by predators may, however, differ between passerines and forest grouse, which are ground nesting and precocial. Whether grouse in our study were capable to perceive predation risk, and adapt nest-site selection reproductive investment accordingly remains an open question and hence is subject to further research.

\section{Acknowledgements}

This study would not have been possible without the endeavour of many fieldworkers, to whom we are very grateful: Panu Halme, Matti Halonen, Heikki Helle, Jenny Hämäläinen, Laura Häsä, Tuomo Jurmu, Janne Kilpimaa, Miina Kovanen, Christophe Lebigre, John Loehr, Ulla-Stiina Mahlamäki, Eeli Mykkänen, Reea Mäkinen, Laura Okkonen, Tuomo Pihlaja, Elina Rantanen, Raimo Saunanen and Ilona Yliniemi. This study was funded by the Maj and Tor Nessling Foundation, the Kone Foundation and the Finnish Centre of Excellence in Evolutionary Research. Thanks to Christophe Lebigre and two anonymous referees for useful comments on an early draft of the manuscript.

\section{References}

Alatalo, R. V., Höglund, J., Lundberg, A., Rintamäki, P. T. \& Silverin, B. 1996: Testosterone and male mating success on the black grouse leks. - Proceedings of the Royal Society B 263: 1697-1702.

Andrén, H. 1992: Corvid density and nest predation in relation to forest fragmentation: a landscape perspective. Ecology 73: 794-804.

Andrén, H., Lindström, E. \& Widen, P. 1985: Synchronous short-term population fluctuations of some birds and mammals in Fennoscandia - occurrence and distribution. - Holarctic Ecology 8: 285-298.

Angelstam, P. 1992: Conservation of communities - the importance of edges, surroundings and landscape mosaic structure. - In: Hansson, L. (ed.), Ecological principles of nature conservation: 9-70. Elsevier Applied Science, London.

Baines, D. 1991: Factors contributing to local and regional variation in black grouse breeding in northern Britain. Ornis Scandinavica 22: 264-270.

Bernard, A. 1982: An analysis of black grouse nesting and brood rearing habitats in the French Alps. - Proceedings International Grouse Symposium 6: 12-18.

Brittas, R. \& Willebrand, T. 1991: Nesting habitat and egg predation in Swedish black grouse. - Ornis Scandinavica 22: 261-263.

Burnham, K. P. \& Anderson, D. R. 2002: Model selection and multimodel inference: a practical infotmation-theoretic approach. - Springer, New York.

Byholm, P., Nikula, A., Kenttä, J. \& Taivalmäki, J.-P. 2007: Interactions between habitat heterogeneity and food affect reproductive output in a top predator. - Journal of Animal Ecology 76: 392-401.

Caizergues, A. \& Ellison, L. N. 1997: Survival of black grouse (Tertrao tetrix) in the French Alps. - Wildlife Biology 3: 177-186.

Eggers, S., Griesser, M., Nystrand, M. \& Ekman, J. 2005: Predation risk induces changes in nest-site selection and clutch size in the Siberian jay. - Proceedings of the Royal Society B 273: 701-706.

Esseen, P. A., Ehnström, B., Ericson, L. \& Sjöberg, K. 1992: Boreal forests - the focal habitats of Fennoscandia. - In: Hansson, L. (ed.), Ecological principles of nature conservation: 252-325. Elsevier Applied Science, London.

Fontaine, J. J. \& Martin, T. E. 2006a: Parent birds assess nest 
predation risk and adjust their reproductive strategies. Ecology Letters 9: 428-434.

Fontaine, J. J. \& Martin, T. E. 2006b: Habitat selection responses of parents to offspring predation risk: an experimental test. - American Naturalist 168: 811-818.

Hansson, L. 1992: Landscape ecology of boreal forests. Trends in Ecology and Evolution 7: 299-302.

Hansson, L. \& Henttonen, H. 1988: Rodent dynamics as community processes. - Trends in Ecology and Evolution 3: 195-200.

Heikkilä, H., Lindholm, T. \& Jaakkola, S. 2002: A guide for the restoration of peatland habitats. - Metsähallituksen luonnonsuojelujulkaisuja B66. [In Finnish with English summary].

Helle, P., Lindén, H. \& Wikman, M. 2002: Metsäkanalintujen viimeaikaisista runsaudenmuutoksista Suomessa. - The Yearbook of the Linnut Magazine 2002: 92-92.

Helminen, M. 1963: Composition of the Finnish populations of capercaillie, Tetrao urogallus, and black grouse, Lyurus tetrix, in the autumns of 1953-1961, as revealed by a styudy of wings. - Papers in Game Reserach 23: $1-24$.

Henttonen, H. 1989: Does an increase in the rodent and predator densities, resulting from modern forestry, contribute to the long-term decline in Finnish tetraonids. - Suomen Riista 35: 83-90. [In Finnish with English summary].

Höglund, J., Alatalo, R. A. \& Lundberg, A. 1992: The effect of parasites on male ornaments and female choice in the lek-breeding black grouse (Tetrao tetrix). - Behavioural Ecology and Sociobiology 30: 71-76.

Hudson, P. J. 1986: The effect of a parasitic nematode on the breeding production of red grouse. - Journal of Animal Ecology 55: 85-92.

Hudson, P. J., Dobson, A. P. \& Newborn, D. 1992: Do parasites make prey more vulnerable to predation? - Journal of Animal Ecology 61: 681-692.

Huhta, E. 1996: Effects of forest fragmentation on reproductive success of birds in boreal forests. - Ph.D. thesis, University of Jyväskylä.

Hyvämäki, T. 2002: Tapion taskukirja (24th ed.). - Metsäkustannus $\mathrm{Oy}$.

Jaenike, J. \& Holt, T. D. 1991: Genetic variation for habitat preference: evidence and explanations. - American Naturalist 137: 67-90

Kauhala, K. \& Helle, P. 2002: The impact of predator abundance on grouse populations in Finland - a study based on wildlife monitoring counts. - Ornis Fennica 79: 14-25.

Kurki, S. \& Lindén, H. 1995: Forest fragmentation due to agriculture affects the reproductive success of ground nesting black grouse. - Ecography 18: 109-113.

Kurki, S., Helle, P., Lindén, H. \& Nikula, A. 1997: Breeding success of black grouse and capercaillie in relation to mammalian predator densities on two spatial scales. Oikos 79: 301-310.

Kurki, S., Nikula, A., Helle, P. \& Lindén, H. 1998: Abundance of red fox and pine marten in relation to the composition of boreal forest landscapes. - Journal of Animal Ecology 67: 874-886.
Kurki, S., Nikula, A., Helle, P. \& Lindén, H. 2000: Landscape fragmentation and forest composition effects on grouse breeding success in boreal forests. - Ecology 81: 1985-1997.

Lebigre, C. 2008: Mating behaviour of the black grouse. Genetic characteristics and physiological consequences. - Ph.D. thesis, University of Jyväskylä.

Lindén, H., Helle, E., Helle, P. \& Wikman, M. 1996: Wildlife triangle scheme in Finland: methods and aims for monitoring wildlife populations. - Finnish Game Research 49: 4-11.

Lindström, E. R., Andrén, H., Angelstam, P., Cederlund, G., Hörnfeldt, B., Jäderberg, L., Lemnell, P.-A., Martinsson, B., Sköld, K. \& Swenson, J. E. 1994: Disease reveals the predator: sarcoptic mange, red fox predation, and prey populations. - Ecology 75: 1042-1049.

Ludwig, G. X. 2007: Mechanisms of population declines in boreal forest grouse. - Ph.D. thesis, University of Jyväskylä.

Ludwig, G. X., Alatalo, R. V., Helle, P., Lindén, H., Lindström, J. \& Siitari, H. 2006: Short- and long-term population dynamical consequences of asymmetric climate change in black grouse. - Proceedings of the Royal Society B 273: 2009-2016.

Ludwig, G. X., Alatalo, R. A., Hele, P., Nissinen, K. \& Siitari, H. 2008: Large-scale drainage and breeding success in boreal forest grouse. - Journal of Applied Ecology 45: 325-333.

Marcström, V., Kenward, R. E. \& Engren, E. 1988: The impact of predation on boreal tetraonids during vole cycles: an experimental study. - Journal of Animal Ecology 57: 859-872.

Marjakangas, A. \& Törmälä, L. 1997: Female age and breeding performance in a cyclic population of black grouse Tetrao tetrix. - Wildlife Biology 3: 195-203.

Martin, T. E. 1992: Breeding productivity considerations: what are the appropriate habitat features for management. - In: Hagan, J. M. \& Johnston, D. W. (eds.), Ecology and conservation of Neotropical migrants: 455-473. Smithsonian Institution, Washington,

Martin, T. E. 1995: Avian life history evolution in relation to nest sites, nest predation, and food. - Ecological Monographs 65: 101-127.

Martin, T. E. 1998: Are microhabitat preferences of coexisting species under selection and adaptive? - Ecology 79: 656-670.

Morris, D. W. 2003: Towards an ecological synthesis: a case for habitat selection. - Oecologia 136: 1-13.

Rätti, O., Dufva, R. \& Alatalo, R. A. 1993: Blood parasites and male fitness in the pied flycatcher. - Oecologia 96 : $410-414$.

Reif, V., Tornberg, R., Jungell, S. \& Korpimaäki, E. 2001: Diet variation of common buzzards in Finland supports the alternative prey hypothesis. - Ecography 24: 267-274.

Ricklefs, R. E. 1969: An analysis of nesting mortality in birds. - Smithsonian Contributions of Zoology 9: 1-48.

Schlaepfer, M. A., Runge, M. C. \& Sherman, P. W. 2002: Ecological and evolutionary traps. - Trends in Ecology and Evolution 17: 474-480. 
Siivonen, L. 1958: Metsälintukatojen perussyistä ja saatujen tulosten soveltavuusmahdollisuuksista. - Suomen Riista 12: 43-54.

Storaas, T. \& Wegge, P. 1987: Nesting habitats and nest predation in sympatric populations of capercaillie and black grouse. - Journal of Wildlife Management 51: 167-172.

Storaas, T., Kastdalen, L. \& Wegge, P. 1999: Detection of forest grouse by mammalian predators: a possible explanation for high brood losses in fragmented landscapes. - Wildlife Biology 5: 187-192.

Thirgood, S., Redpath, S. M., Rothery \& Aebischer, N. J. 2000: Raptor predation and population limitation in red grouse. - Journal of Animimal Ecology 69: 504-516

Willebrand, T. 1992: Breding and age in female black grouse Tetrao tetrix. - Ornis Scandinavica 23: 29-32. 